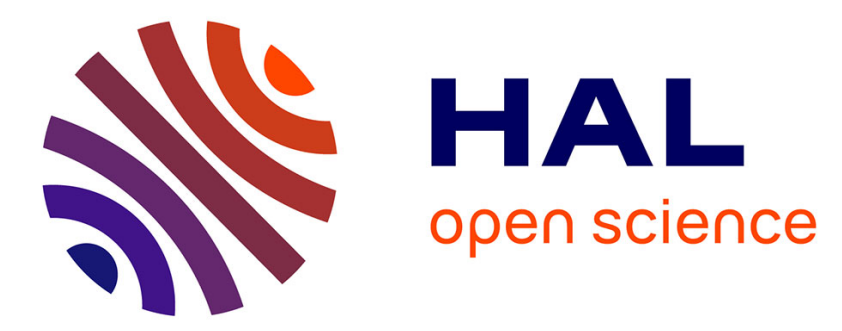

\title{
Influence of projectile shape on dynamic behavior of steel sheet subjected to impact and perforation
}

K. M. Kpenyigba, Tomasz Jankowiak, Alexis Rusinek, Raphaël Pesci

\section{To cite this version:}

K. M. Kpenyigba, Tomasz Jankowiak, Alexis Rusinek, Raphaël Pesci. Influence of projectile shape on dynamic behavior of steel sheet subjected to impact and perforation. Thin-Walled Structures, 2013, 65, pp.93-104. 10.1016/j.tws.2013.01.003 . hal-00952580

\section{HAL Id: hal-00952580 \\ https://hal.science/hal-00952580}

Submitted on 27 Feb 2014

HAL is a multi-disciplinary open access archive for the deposit and dissemination of scientific research documents, whether they are published or not. The documents may come from teaching and research institutions in France or abroad, or from public or private research centers.
L'archive ouverte pluridisciplinaire HAL, est destinée au dépôt et à la diffusion de documents scientifiques de niveau recherche, publiés ou non, émanant des établissements d'enseignement et de recherche français ou étrangers, des laboratoires publics ou privés. 


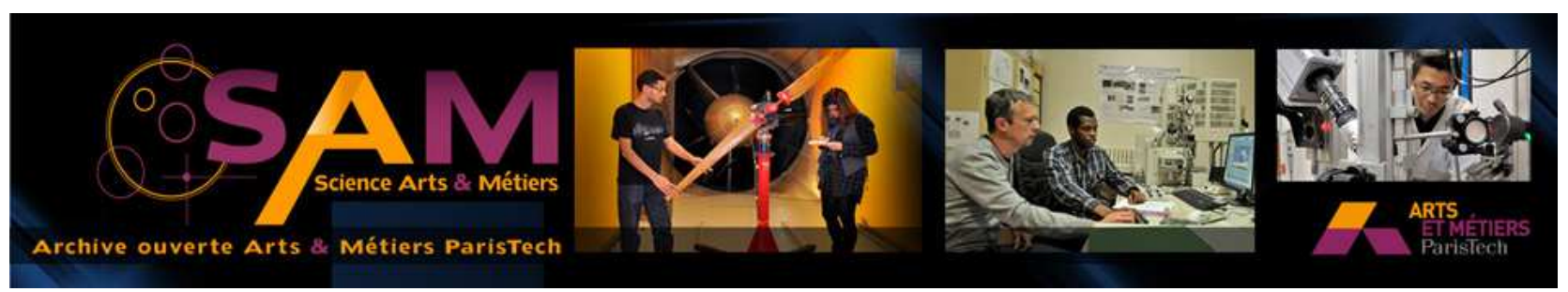

\section{Science Arts \& Métiers (SAM)}

is an open access repository that collects the work of Arts et Métiers ParisTech researchers and makes it freely available over the web where possible.

This is an author-deposited version published in: http://sam.ensam.eu

Handle ID: .http://hdl.handle.net/10985/7804

\section{To cite this version :}

K. M. KPENYIGBA, Tomasz JANKOWIAK, Alexis RUSINEK, Raphaël PESCI - Influence of projectile shape on dynamic behavior of steel sheet subjected to impact and perforation - ThinWalled Structures - Vol. 65, p.93-104 - 2013 


\title{
Influence of projectile shape on dynamic behavior of steel sheet subjected to impact and perforation
}

\author{
K.M. Kpenyigba ${ }^{\text {a,* }}$, T. Jankowiak ${ }^{\mathrm{b}}$, A. Rusinek ${ }^{\mathrm{a}}$, R. Pesci ${ }^{\mathrm{c}}$ \\ a National Engineering School of Metz, Laboratory of Mechanics, Biomechanics, Polymers and Structures, 1 route d'Ars Laquenexy cs65820 57078 Metz Cedex 3, France \\ ${ }^{\mathrm{b}}$ Institute of Structural Engineering, Poznan University of Technology, Piotrowo 5, Poznan, Poland \\ c LEM3 UMR CNRS 7239, ENSAM-Arts et Métiers ParisTech CER of Metz, 4 rue Augustin Fresnel 57078 Metz Cedex 3, France
}

Keywords:

Experiments

Perforation

Ballistic

Numerical simulation

Dynamic failure

\begin{abstract}
A B S T R A C T
The paper describes a work focused on the process of perforation of steel sheet. Experimental, analytical and numerical investigations have been carried out to analyze in details the perforation process. Based on these approaches, the ballistic properties of the material and the failure modes depending on the projectile nose shape (conical, blunt or hemispherical) have been studied. Different failure modes have been observed, including petaling, plug ejection and circumference necking. The special study about the number of petals has been done for different nose angles using conical shape projectiles. The complete energy balance is also reported and the absorbed energy by the steel sheet has been obtained by measuring initial and residual projectile velocities. A wide range of impact velocities from 35 to $180 \mathrm{~m} / \mathrm{s}$ has been covered during the tests. All the projectiles are $13 \mathrm{~mm}$ in diameter and the plates are $1 \mathrm{~mm}$ thick. Moreover, the mass ratio (projectile mass/steel sheet mass) and the ratio between the span of the steel sheet and the diameter of the projectile are constant, equal to 0.38 and 3.85 , respectively.
\end{abstract}

\section{Introduction}

Among impact problems and other related topics, the penetration and the perforation of thin metallic plates by non-deformable projectiles have long been of interest. Several studies related to this subject are available in international literature. Atkins et al. [1], Borvik et al. [2-5] and Rodriguez-Martinez et al. [6]. Backman et al. [7] have revisited the perforation of projectiles into target and proposed an analytical model for ballistic velocities based on damage mechanisms. Chen et al. [8] have compared two analytical models of ballistic curves and emphasize that the models of Forrestal et al. [9] and Chen et al. [10] are only applicable to the perforation of ductile metal plates by rigid sharp-nose projectiles. The petaling failure mode of circular plates under explosive and impact loading was developed by Wierzbicki [11], where the total energy absorbed by the system, the number of petals and the final deformed shape of the plate were determined as a function of the flow stress and the thickness of the plate as well as the parameters of the external loading. Impact behavior of thin steel plate was recently numerically studied by Rodriguez-Martinez et al. $[6,12]$; they showed that the failure mode of the impacted sheet is strongly linked to the projectile shape. Several failure criteria which are usually used in FE codes were examined by
Wierzbicki et al. [13,14]; they pointed out that the failure strain formulated as a function of the stress triaxiality would be the most suitable for a variety of problems and the general form of this type of failure strain can be written as

$\varepsilon_{f}=f(\eta)=f\left(\frac{\sigma_{m}}{\bar{\sigma}}\right)$

where $\varepsilon_{f}$ is the effective plastic strain to failure and $\eta$ is the stress triaxiality defined by the ratio of the mean stress $\sigma_{m}$ to the equivalent stress $\bar{\sigma}$.

Atkins et al. [1] proposed an analytical model to define necking and the number of radial cracks formed during perforation in ductile materials by both conical and round-ended projectiles. Alavi et al. [15] investigated penetration of hemispherical nose projectile into layered aluminum and observed a mix of failure modes.

This paper puts the emphasis on experimental ballistic impact coupling with analytical models, and provides more significant information on numerical simulations than that usually observed. Different effects are mixed including, the shape and the mass of the projectile, the thickness of the sheet and the material behavior. That is the reason why it is difficult to interpret how these parameters influence the results. A more detailed analysis seems to be necessary for a better and more complete understanding of the steel sheet perforation by different shape rigid projectiles. 
The outline of this paper is the following. The experimental setup and results of perforation are summarized in Section 2. Three projectile shapes are considered: conical, hemispherical and blunt. The analytical model is reported in Section 3 to define the number of petals $N$ depending on the nose angle of the conical shape projectile. All experimental tests are used to validate numerical models which are defined in details in Section 4 of this paper. The most important part in the development of the numerical model is linked to description of the constitutive material together with failure criterion. The material behavior has been modeled using the Johnson-Cook constitutive equation $\bar{\sigma}\left(\bar{\varepsilon}^{p}, \dot{\bar{\varepsilon}}^{p}, T\right)[16,17]$ which takes into account strain hardening, strain-rate sensitivity, and thermal softening. It is important to emphasize that during perforation, an impact velocity of $V_{0}=120 \mathrm{~m} / \mathrm{s}$ allows to reach locally in the impacted zone a strain rate around $600 \mathrm{~s}^{-1}$ and a local heating of $500 \mathrm{~K}[18,19]$. As the duration of the impact is very short, it is necessary to take into account an adiabatic heat transformation inside the elements in the numerical model. Therefore, the constitutive relation is coupled to the heat equation for a complete description of the behavior of the target at high impact velocity under adiabatic conditions. This approach is extensively used in the literature [20-23].

\section{Experimental research methodology for perforation}

This work describes carefully the behavior of the steel sheets under impact loading. The material studied in this work is a lowcarbon ferritic steel containing $0.3-0.4 \% \mathrm{Mn}, 0.1-0.15 \% \mathrm{Al}$ and $0.05 \% \mathrm{Si}$. All the sheets were rolled. The yield stress and the ultimate tensile strength determined through quasi-static tensile tests are, respectively, $\sigma_{y} \approx 154 \mathrm{MPa}$ and $U T S \approx 347 \mathrm{MPa}$.

In the next part, the sequence of the experimental tests is described.

\subsection{Experimental set up description}

During experimental tests, the steel sheets are impacted by a rigid projectile and the mechanical part of the experimental setup is shown in Fig. 1. The projectile is launched using a pneumatic gas gun; it accelerates in the tube $C$ to reach the velocity namely initial impact velocity $V_{0}$. Then, the projectile impacts the steel sheet with partial or complete perforation depending on the quantity of kinetic energy delivered to the material tested. If the initial impact velocity is lower than the ballistic limit $V_{\boldsymbol{B}}$, the projectile does not perforate the structure but it bounces off. The velocity of the projectile after perforation is defined as the residual velocity $V_{R}$. Both initial and residual velocities are measured by velocity sensors D and F. Generally, the minimum projectile velocity which allows a complete perforation is called ballistic limit $V_{\boldsymbol{B}}$. To check the validity and to find the uncertainty of the measurement between the two sensors, several shoots without plates have been performed, part E, Fig. 1. The maximum error on the measurement of the velocity between the two sensors was estimated at $\Delta \bar{V}=1 \mathrm{~m} / \mathrm{s}$. In parallel, the velocity of the projectile was measured using a high speed camera (HSC). A constant velocity between $\mathrm{D}$ and $\mathrm{F}$ has been observed; it is in good agreement with the value obtained using the two aforementioned time counters.

In this study, several projectile shapes, Fig. 2, have been used to analyze their effect on the ballistic curve $V_{R}-V_{0}$. For each projectile, the mass is kept as constant $m_{p} \approx 30 \mathrm{~g}$. The material used for machining the projectile is a Maraging steel with a heat treatment to reach a yield stress of $\sigma_{y}^{\text {projectile }} \approx 2 \mathrm{GPa}$. Therefore, the projectile may be assumed as rigid (without mushroom effect) during the process of perforation.

The dimensions of the plates used during experiments are given, Fig. 3. The active part is $100 \times 100 \mathrm{~mm}^{2}$, the thickness is $1 \mathrm{~mm}$ and it is embedded on a rigid support allowing to reduce sliding effect during the test.

The plate has been impacted by the projectile in the central zone as shown in Fig. 3. A wide range of initial impact velocities was considered for a complete definition of the ballistic curve of the steel sheet, $35 \leq V_{0} \leq 180 \mathrm{~m} / \mathrm{s}$.

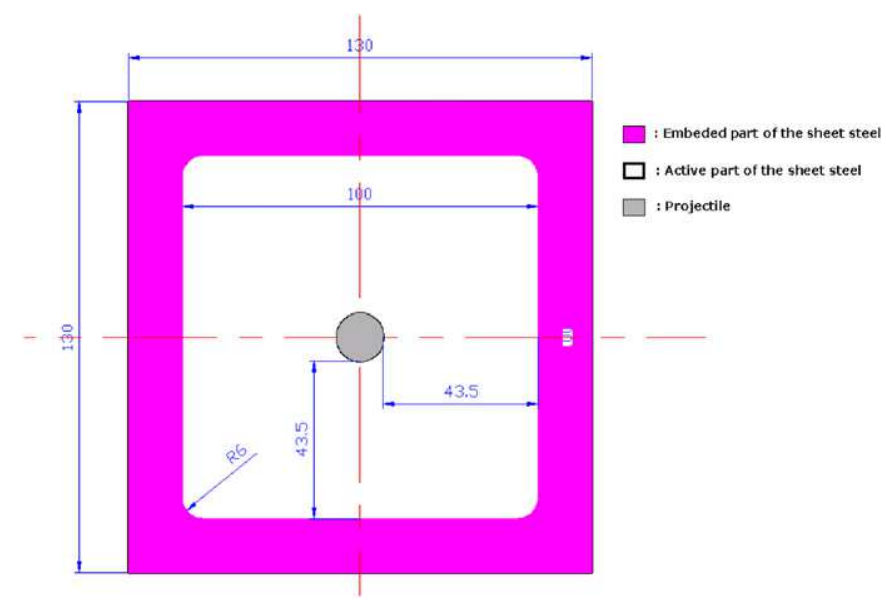

Fig. 3. Geometry of steel plate used during perforation tests, thickness $1 \mathrm{~mm}$.

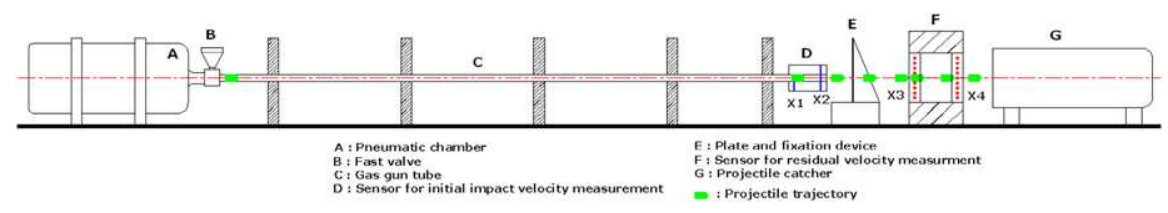

Fig. 1. Experimental device presentation.

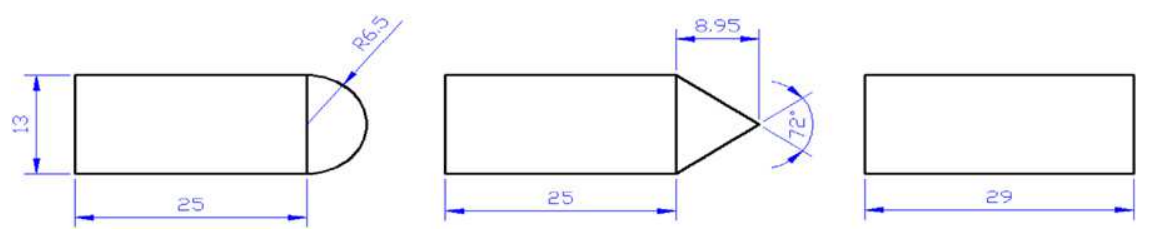

Fig. 2. Projectile shape used to analyze their effect on ballistic curves and energy absorption (constant mass for each configuration). 


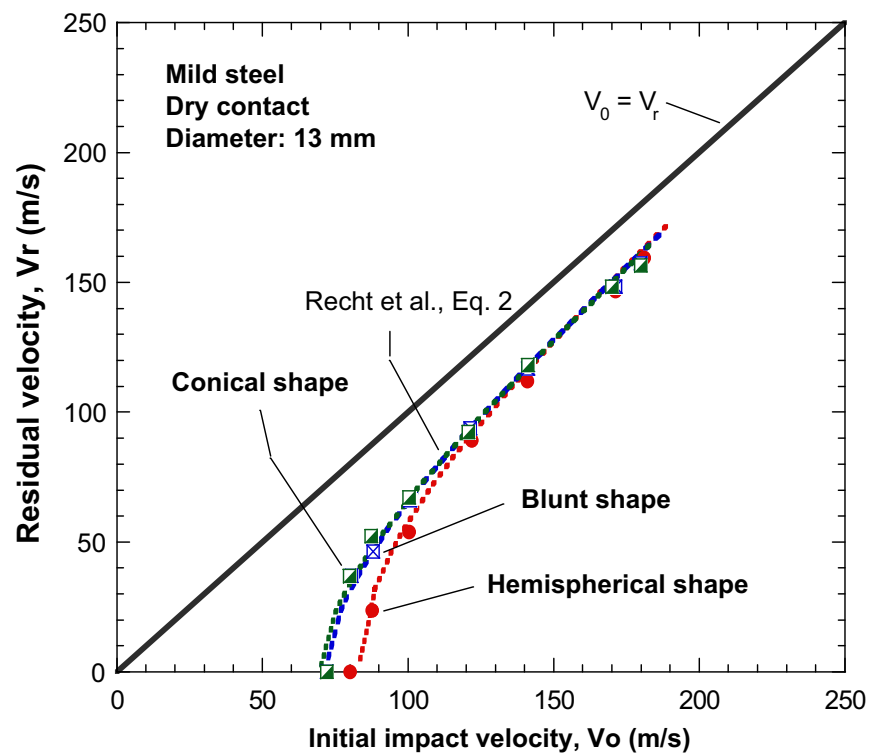

Fig. 4. Experimental ballistic curve depending on the shape of the projectile, thickness plate $t_{0}=1 \mathrm{~mm}$.

Table 1

Fitting parameters based on Eq. (2).

\begin{tabular}{lll}
\hline Conical & Blunt & Hemispherical \\
\hline$\kappa=1.8232$ & $\kappa=1.8801$ & $\kappa=1.9401$ \\
$V_{B}=72 \mathrm{~m} / \mathrm{s}$ & $V_{B}=72 \mathrm{~m} / \mathrm{s}$ & $V_{B}=83.5 \mathrm{~m} / \mathrm{s}$ \\
\hline
\end{tabular}

\subsection{Ballistic curves and energy balance description}

The results in terms of ballistic curve $V_{R}-V_{0}$ are reported in Fig. 4. The contact between the steel sheet and the projectile is considered as dry, $(\mu>0)$. As a first result, it is observed an increase of the ballistic limit $V_{B}$ for a hemispherical shape projectile compared to blunt or conical shapes, Table 1.

In fact, for hemispherical shape projectile, the process of plastic strain localization is with a delay. The steel sheet is flowing along the projectile nose to induce a circumferential necking followed by a plug ejection. This process requires more plastic work than is necessary to just shear a plug out of the target (blunt projectile). This point is reported and discussed in details in literature $[6,24]$. Using a blunt or a conical projectile the failure mode is completely different as it will be discussed later in this section of the paper. The ballistic curves in a general way, Fig. 4, may be fitted using the relation proposed by Recht et al. [25], Eq. (2).

$V_{R}=\left(V_{0}^{\kappa}-V_{B}^{\kappa}\right)^{1 / \kappa}$

where $V_{B}$ is the ballistic limit and $\kappa$ is a fitting parameter.

A comparison between experimental ballistic curves and the fitting equation, Eq. (2) is reported in Fig. 4. It is observed that this approach allows to define properly the shape of the ballistic curves. The parameter $\kappa$ depends on the projectile shape as it is reported in Table 1.

During the perforation of the target, one part of the kinetic energy of the projectile is absorbed by the global target deformation, local plastic flow and failure, and elastic work. The remaining kinetic energy is simply the residual energy of the projectile. Note that for hemispherical and blunt projectile, a small part of

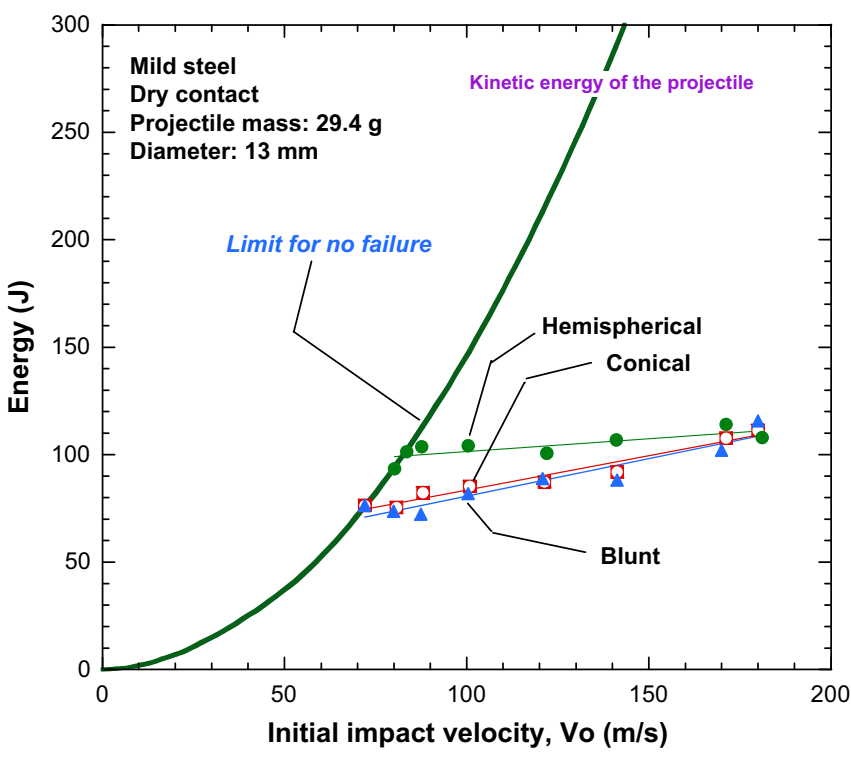

Fig. 5. Energy absorbed by the plate as a function of the initial impact velocity and the projectile shape.

the kinetic energy is lost through ejection of the plug. The energy lost by friction work can be assumed minor in the total energy balance during ballistic impact. The maximum kinetic energy that can reach the projectile during the test is $486 \mathrm{~J}$. Knowing $V_{0}$ and $V_{R}$ velocities, the global energy absorbed by the plate during perforation, $W_{\text {plate }}\left(V_{0}\right)$, is calculated, Eq. (3).

$W_{\text {plate }}=\frac{1}{2} m_{p}\left(V_{0}^{2}-V_{R}^{2}\right)$

The results for different projectile shapes are presented, Fig. 5. The energy absorbed by the plate $W_{\text {plate }}\left(V_{0}\right)$ before failure is approximately the same using a blunt or a conical projectile and it is lower than that obtained by using hemispherical projectile, Fig. 5. This seems reasonable because of the process of plastic flow which is more important using hemispherical projectile as we have pointed out rather. However, at high impact velocity, up to $170 \mathrm{~m} / \mathrm{s}$, the energy less depends on the projectile shape, in comparison with the values close to the ballistic limit $V_{B}$. This is similar to the experimental results obtained by Landkof and Goldsmith [26] who have shown that at relatively high impact velocities compared to the ballistic limit the influence of the nose shape on the energy absorbed is negligible.

The failure mode of the steel sheet is analyzed and it is found that the projectile shape has a strong influence on the process of failure, Fig. 6. For a blunt projectile, a process of high speed cutting due to high shearing is observed inducing a plug ejection. As the thickness of the sheet is small, there is high localization of the plastic strain in the very small shear zone during perforation. The plastic deformation is limited to the immediate vicinity of the impacted zone. For a conical shape projectile a failure mode by petaling occurs inducing radial necking due to a process of piercing. The conical projectile pierces the target easily and the plastic strain is localized at the ends of the petals. As it will be discussed in Section 3, the number of petals $N$ is directly linked to the projectile nose angle $\phi$ in the case of conical shape. Concerning hemispherical projectile, the steel sheet fails by plug ejection due to a circumferential necking. It is followed by radial cracks due to the process of radial hole expansion as discussed in [1]. For all cases discussed here, the stress triaxiality is different near the failure zone as it will be reported in the numerical part, Section 4. 
a

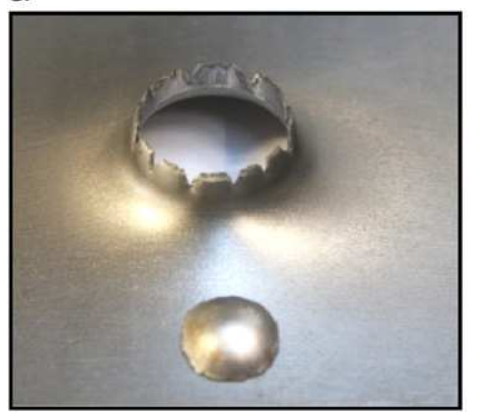

b

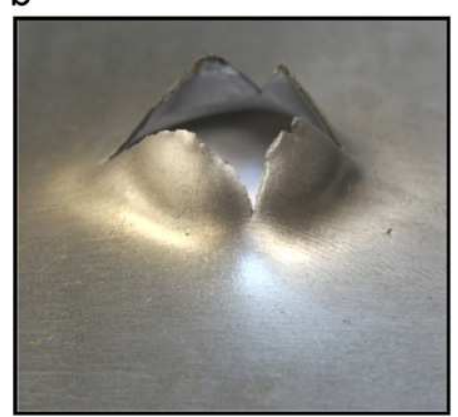

C

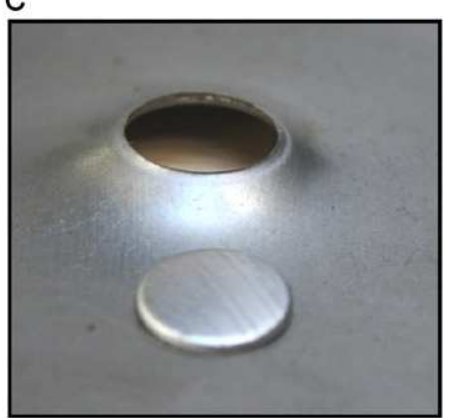

Fig. 6. Experimentally observed failure patterns for different kinds of projectile, $V_{0}=141 \mathrm{~m} / \mathrm{s}$ and dry condition. (a) Hemispherical; (b) conical; and (c) blunt.
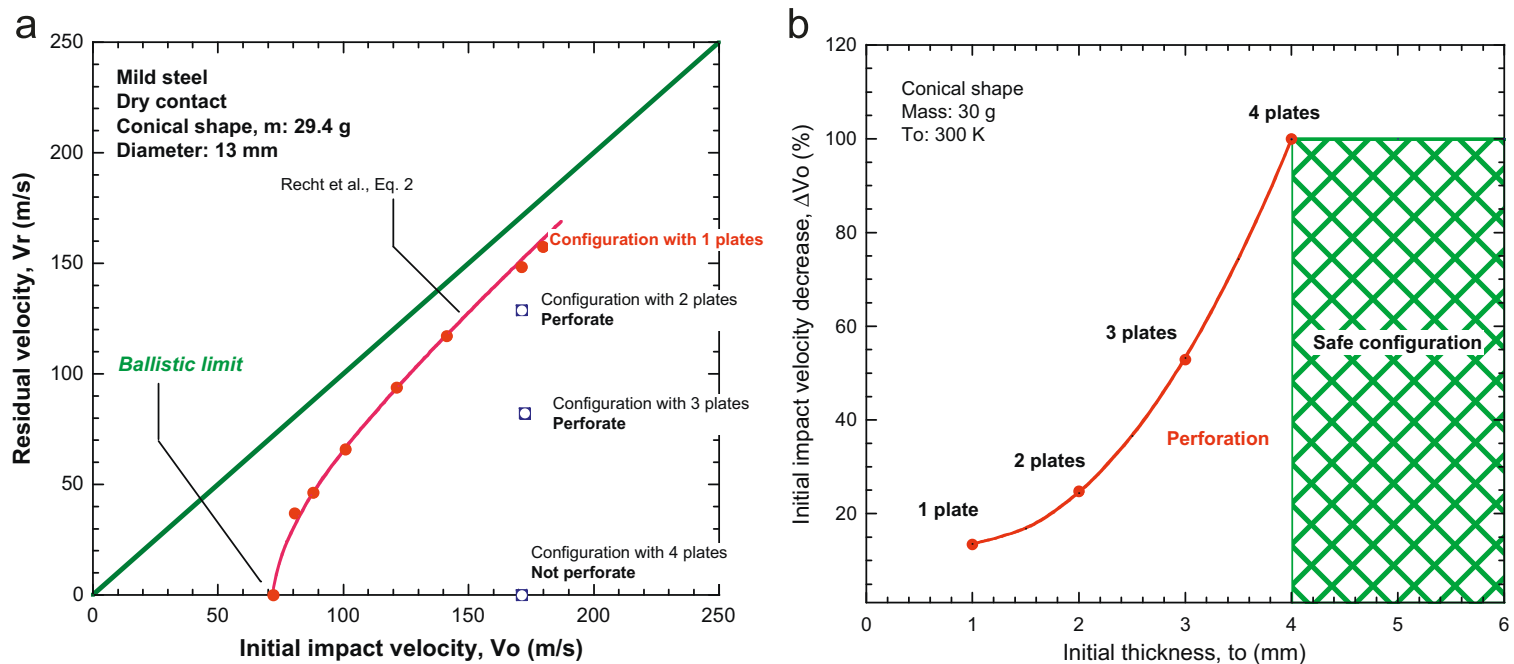

Fig. 7. (a) Residual velocity depending on the initial impact velocity; and (b) decrease of the initial impact velocity with thickness configuration.

Many studies have investigated the opportunity of improving impact performance by layering the targets, which offers a wide range of thickness configurations [27-29]. In this work, a sandwich configuration has been investigated. Thus, several tests have been performed using one up to four stacked plates without any adhesion, Fig. 7. The thickness of each plate constituting the sandwich is $1 \mathrm{~mm}$. For an imposed initial impact velocity $V_{0}$, the energy absorbed by the structure configuration increases with the number of plates, Table 2 . In the case of four plates, the conical projectile is stopped for an initial impact velocity of $V_{0}=172 \mathrm{~m} / \mathrm{s}$, Fig. 7a. The relation between the number of plates (or thickness) and the residual velocity $V_{R}$ is reported, Fig. $7 \mathrm{~b}$. A non-linear relation is noticed between the number of plates and the velocity decrease, $\Delta V_{0}$. This mean that the relation between the ballistic limit and the number of plates in the sandwich configuration is not linear. More results and details on the study of impact resistance of a monolithic structure compared to a sandwich configuration with the same thickness are reported in [30,31].

Based on the last case (four plates sandwich), a mix of the previously described failure modes has been observed, Fig. 8 . The failure mode changed from circumferential necking to petaling. The plate IV, impacted first, failed by circumferential necking due to the process of radial hole enlargement. Color changes were also noticed around the hole, supposing high temperature increase [32]. This point will be discussed in session 3. For plate III both circumferential necking and radial cracks failure mode were
Table 2

Energy absorption in relation to the number of plates.

\begin{tabular}{lllll}
\hline Configuration & 1 Plate & 2 Plates & 3 Plates & 4 Plates \\
\hline$V_{0}(\mathrm{~m} / \mathrm{s})$ & 172 & 172 & 172 & 172 \\
$\left.W_{\text {plate }} \mathrm{J}\right)$ & 107.89 & 187.18 & 337.63 & 431.01 \\
\hline
\end{tabular}

noticed. Finally the failure of both plates II and I is due to petaling in relation to the conical shape, Fig. $6 \mathrm{~b}$. As the thickness of the sandwich configuration is large, there is more plastic work in the impacted zone, which considerably reduces the piercing process observed in the case of one plate configuration.

For all the tests described previously, dry contact between the conical projectile and the steel sheet plate has been used, $\mu>0$. As the surface contact is large for conical shape, $l_{\text {contact }}=$ $\phi_{p} / 2 \cdot[\tan (\phi / 2)]^{-1}$, a study has been performed to analyze the friction effect. Therefore several lubricants have been used, Table 3.

As a result, one can observe that the lubrication of the contact surface does not change considerably the results in term of residual velocity and therefore of kinetic energy absorbed, Table 3. As it is reported, the residual velocities using a fresh glue (reducing sliding) or grease are very close. For this reason a friction coefficient equal to $\mu=0.2$ will be assumed during 


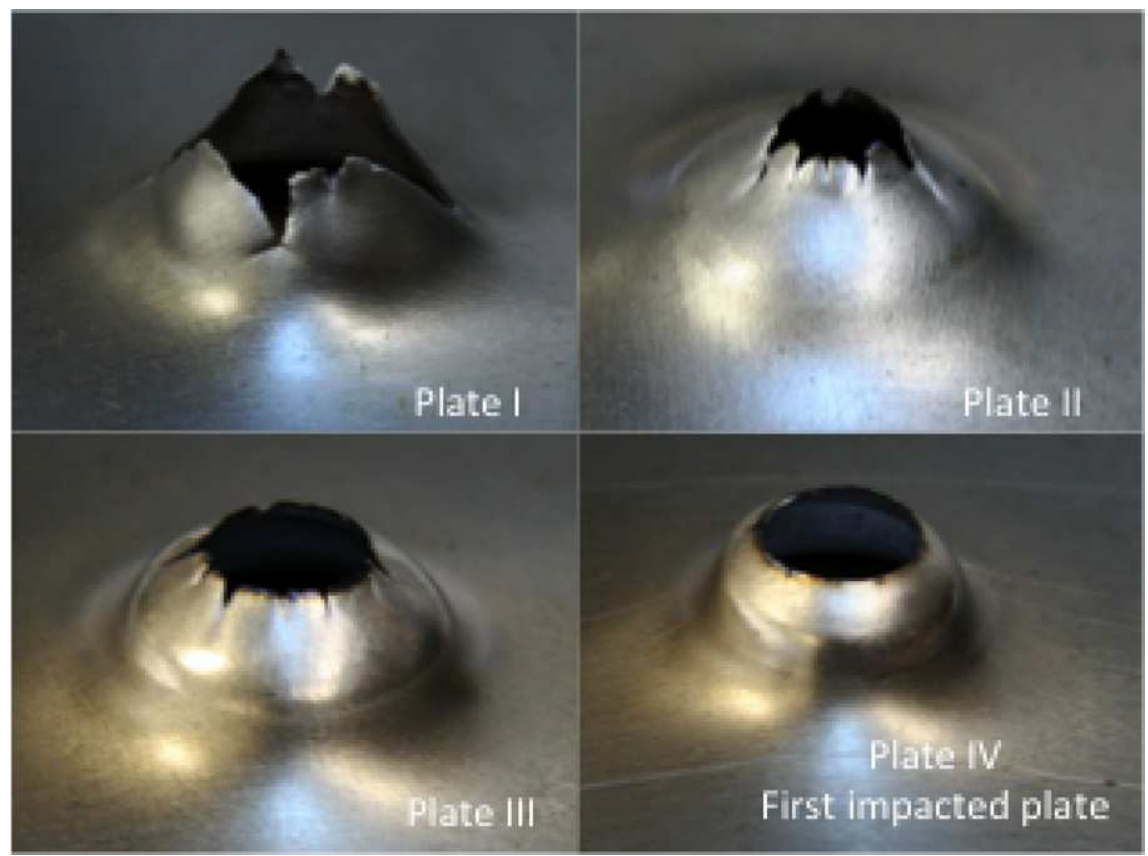

Fig. 8. Mixed failure mode observed for steel sheet sandwich using a conical projectile shape, $V_{0}=172 \mathrm{~m} / \mathrm{s}$ for dry contact.

Table 3

Friction effect on perforation process using a conical shape projectile $\left(\phi / 2=36^{\circ}\right)$, a steel sheet thickness of $t_{0}=1 \mathrm{~mm}$.

\begin{tabular}{llllll}
\hline Contact surface & Dry & Fresh glue & Grease $\mathbf{M o S}_{\mathbf{2}}$ & Oil & Teflon \\
\hline$V_{0}(\mathrm{~m} / \mathrm{s})$ & 122 & 122 & 122 & 122 & 122 \\
$V_{R}(\mathrm{~m} / \mathrm{s})$ & 27.609 & 27.51 & 27.51 & 26.8 & 27.51 \\
\hline
\end{tabular}
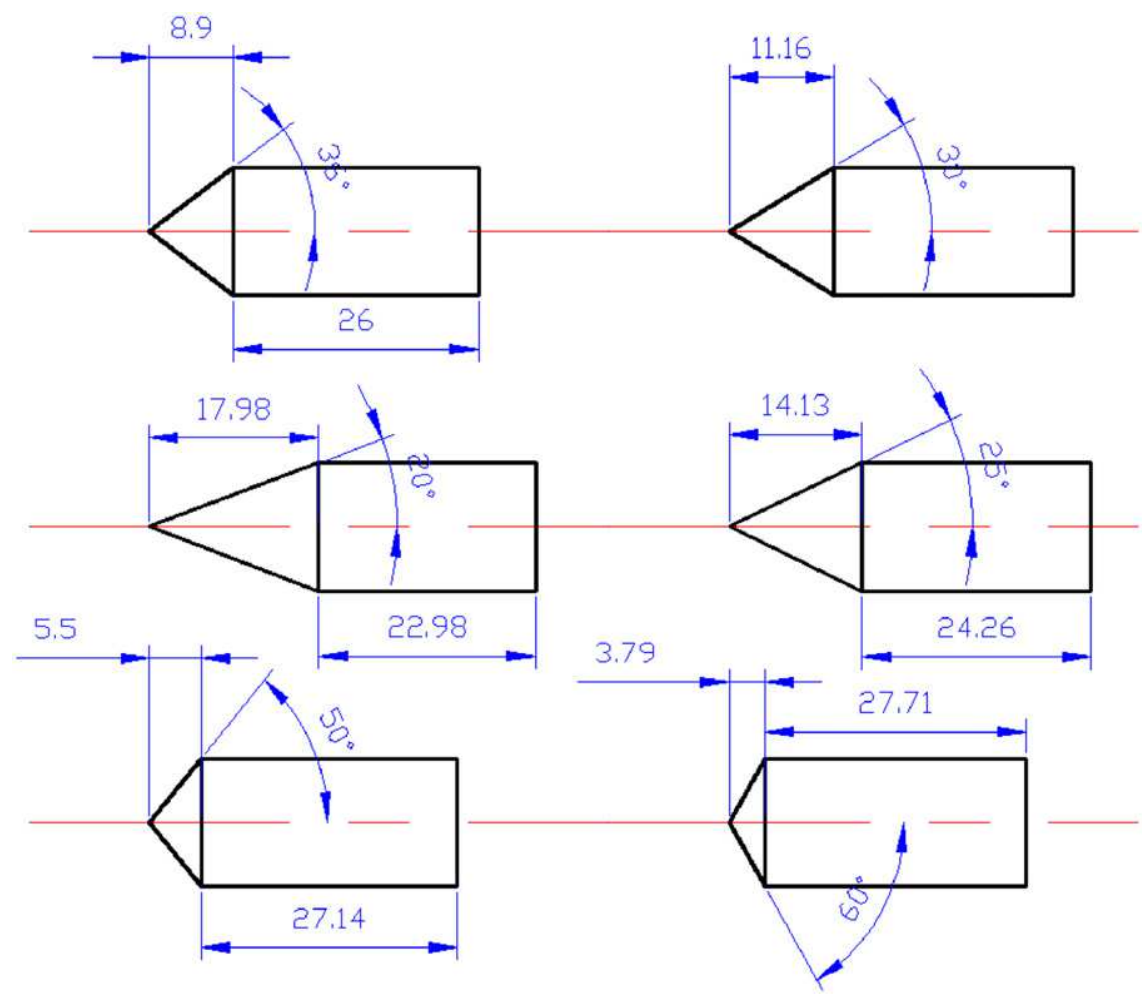

Fig. 9. Conical projectile shape used during experiments. 
numerical simulations. This value is frequently used for a contact steel-steel without lubricant [6,33].

In the next part of this paper, the nose projectile angle effect on the failure mode is studied considering a conical shape.

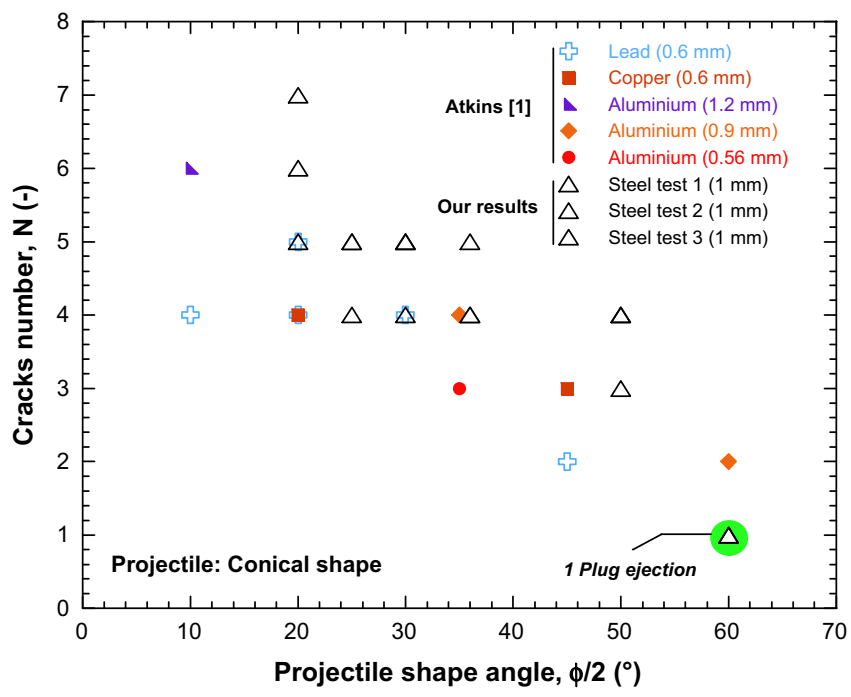

Fig. 10. The number of petals as function of the projectile shape angle.

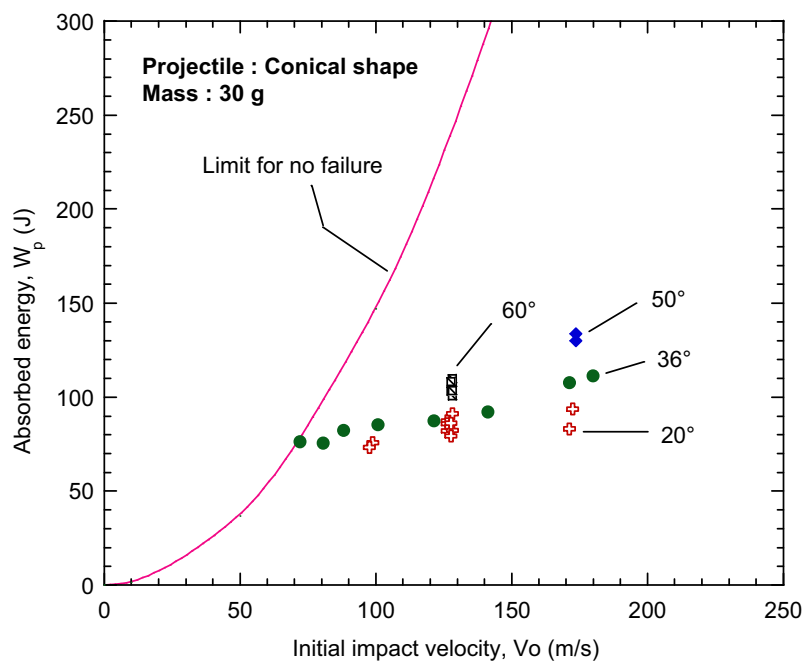

Fig. 11. Energy absorbed by the plate in relation to the nose projectile angle.

\section{Experimental study and analytical prediction of the numbers of petals}

As it is reported in $[1,26]$, the number of petals $N$ observed during dynamic perforation coupled to a conical projectile shape is related to the nose angle $\phi$. The first available rigorous experimental and analytical investigation of the petaling problem was carried out by Landkof and Goldsmith [26]. A more recent work of Wierzbicki propose a close form solutions of the number of petals that form using conical projectile based on the minimization of the total energy absorbed by the petals [11]. In our case, several angles have been used varying from $20 \leq \phi / 2 \leq 60^{\circ}$, Fig. 9. As before, the projectiles are made of Maraging steel in order to avoid mushroom effect. It has to be noticed that all projectiles have the same mass, $m_{p} \approx 30 \mathrm{~g}$ allowing to keep the same amount of kinetic energy for an imposed impact velocity. Therefore, the main parameter studied in this section is the projectile shape effect.

The experimental results are shown in Fig. 10, for a half angle $\phi / 2$ varying from 10 to $60^{\circ}$. For all considered cases three experiments were performed to confirm the reproducibility of the test. Analyzing the results it is observed that generally the number of petals $N$ decreases when the projectile angle $\phi / 2$ increases, Fig. 10.

The results in terms of absorbed energy are reported on the following curve, Fig. 11. It is visible on this graph that a rise in angle allows to increase the energy absorbed by the plate. When the angle decreases, the process of piercing reduces the energy absorbed by the steel sheet, Fig. 11 . For the cone angle $\phi / 2=60^{\circ}$ the energy absorbed by the plate is almost the same as for blunt projectile. From this angle there is a transition in the failure mode from petaling to plug ejection.

The experimental results in terms of the number of petals $N$ as a function of the nose projectile angle $\phi / 2$ using a conical shape are shown in Fig. 12.

As previously mentioned in this work and discussed in the paper published by [1], the failure mode of a steel sheet under impact perforation is strongly dependent on the projectile nose shape. Atkins et al. analyzed in detail the petals forming in thin plates impacted by conical and spherical projectiles and proposed an analytical model to evaluate the numbers of necks and radial cracks which occurs. Based on the work of [1], the number of petals $N$ can be estimated using a conical projectile.

In the model of Atkins, the material behavior is described using the following constitutive relation, $\bar{\sigma}=\sigma_{0} \cdot\left(\bar{\varepsilon}^{p}\right)^{n}$. The key parameter is mainly the hardening coefficient $n$ that affects the stiffness of the material. The whole analytical description is

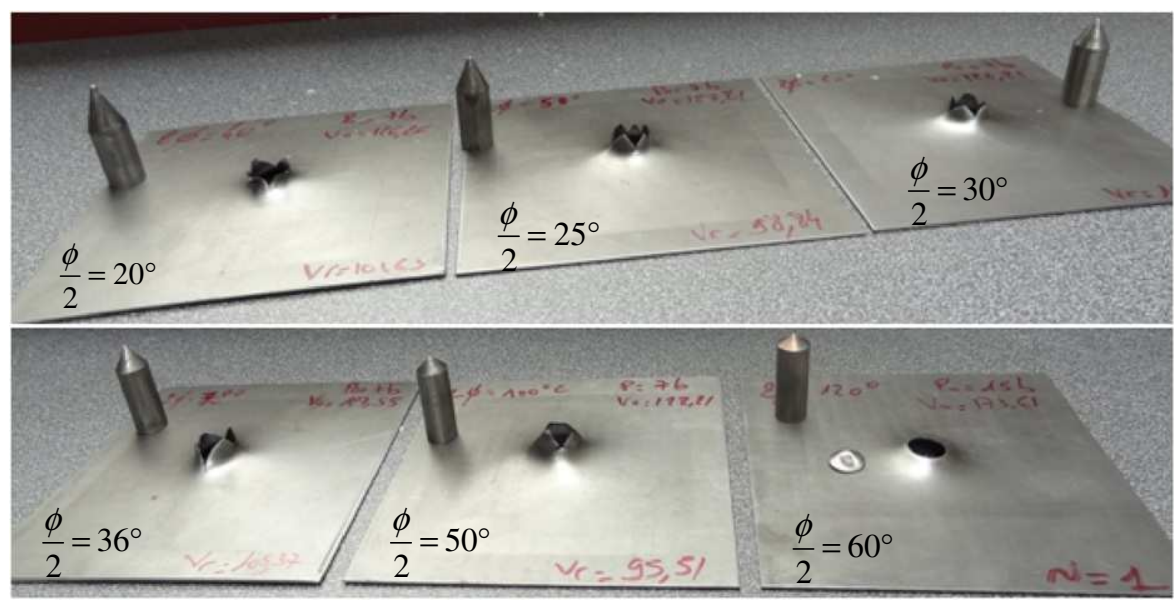

Fig. 12. Effect of conical projectile angle on the number of petals $N$ and failure mode. 
reported in details in [1]. In this work, just the final formulation of the number of petals $N$ is reported, Eq. (4).

$N=\frac{\pi Y}{R}\left\{2 n r_{0}+\frac{[\exp (n)-\sin (\phi)]}{(d t / d r)}\left[\frac{1}{\exp (2 n)}-\frac{1}{\exp \left(2 \varepsilon_{\mathrm{f}}\right)}\right] \cdot t_{0}\right\}$

where $Y$ is the yield strength of the material, $R$ is the fracture toughness, $r_{0}$ is the starter hole radius in the target, $d t / d r$ is the thickness distribution along the necking propagation, $\varepsilon_{f}$ is the failure strain level and $t_{0}$ is the thickness of the plate.

It must be noticed that the expression of $N$, Eq. (4), gives a trend since the number of petals formed after perforation of the steel sheet must be an integer number.

The model is based on an initial hole enlargement due to radial expansion. Thus the initial hole radius $r_{0}$ is defined as follows, Eq. (5). This quantity is linked to the thickness of the steel sheet $t_{0}$ and the nose projectile angle $\phi$.

$r_{0}=\frac{t_{0}}{2} \cdot \tan (\phi)$

For a thickness varying from 0.66 to 1.5 , the fracture thickness may be assumed as follows, Eq. (6).

$R=\frac{Y \cdot t_{0}}{0.8}$

Based on this analytical model, all parameters are fixed except the quantity $d t / d r$. In [1], the value is varying $0.07 \leq d t / d r \leq 0.09$. A larger value allows to decrease $N$. The key parameter to define the number of petals is the failure strain level, $\varepsilon_{f}$. To estimate it, a numerical simulation in tension has been performed. Comparing the macroscopic response in terms of behavior $\sigma-\varepsilon$ with experiment, the local equivalent strain in the necking zone for a macroscopic failure at $\varepsilon_{f}^{\text {macroscopic }}=0.26$ is equal to $\varepsilon_{f}^{\text {local }}=0.8$ under adiabatic conditions and $\varepsilon_{f}^{\text {local }}=0.4$ for isothermal conditions. Based on this local approach, the thermal effect can be studied. It induces a delay in the process of instability allowing to keep an homogeneous distribution of the plastic strain for longer. This effect was discussed for several cases in [34]. However, when the condition of instability of the plastic strain is reached, the necking growth is faster along the radial direction. The following

Table 4

Parameters used to describe the number of petals, Eq. (4)

\begin{tabular}{llll}
\hline$n(-)$ & $Y(\mathrm{MPa})$ & $\varepsilon_{f}^{\text {adiabatic }}(-)$ & $\varepsilon_{f}^{\text {isothermal }}(-)$ \\
\hline 0.18 & 200 & 0.8 & 0.4 \\
\hline
\end{tabular}

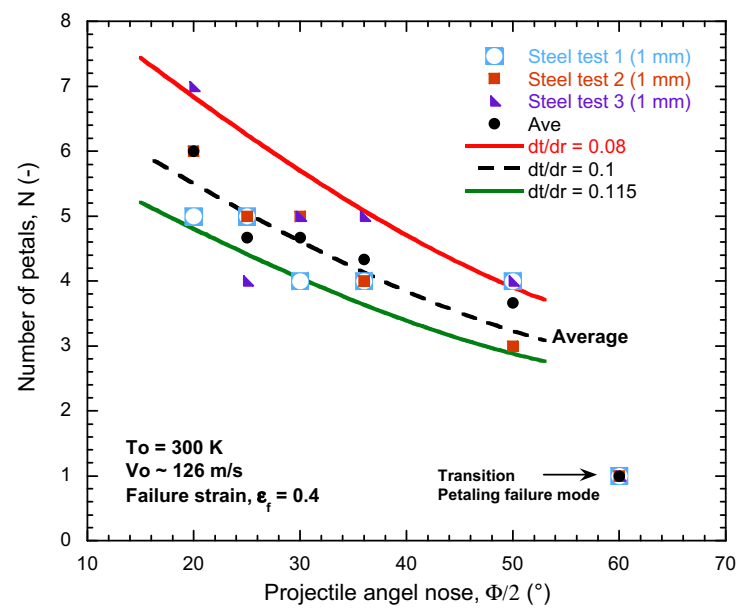

chart, Table 4, is reporting the main quantities used to define the mechanical behavior of the material.

On the next curves are reported the analytical predictions compared with experiments, Fig. 13. It may be observed that a good agreement is obtained between analytical results and experiments if the failure strain level is defined under isothermal or adiabatic conditions. However, considering a failure strain definition under adiabatic conditions the thickness distribution along the necking propagation has to be larger. Considering isothermal conditions, the value for $d t / d r$ is close to the value reported in [1].

For $\phi / 2>50^{\circ}$, the model not allows to predict properly experimental observation. In fact a failure mode by plug ejection is observed, Fig. 12, which is similar to that obtained with a blunt projectile, Fig. 6c.

To define in a precise way the process of perforation, numerical simulations are performed by taking into account the material behavior and the boundary conditions in order to predict the number of petals $N$ depending of the projectile nose angle $\phi / 2$ and the ballistic curve. Numerical simulations are then compared with experiments and the analytical model proposed by Atkins et al. [1].

\section{Numerical simulation of the perforation process}

In this section, the numerical modeling methodology is presented. The numerical model and the description of both initial and boundary conditions are described. In addition, the constitutive relation of the material together with the failure criterion are reported. The numerical results are also included and are compared with experimental data.

\subsection{Description of the numerical model}

Abaqus/Explicit finite element code is used to simulate the perforation process and the model is reported in Fig. 14. The optimal mesh has been obtained using a convergence method (stability of the results without mesh dependency). The smaller element size $\Delta x$ defines directly the integration time step $\Delta t \propto \Delta x / C_{0}$ via elastic wave speed $C_{0}=\sqrt{E / \rho}$. If the element length is strongly reduced the integration time reaches $\Delta t \rightarrow 0$. The mesh is denser in the projectile-plate contact zone to satisfy the conditions proposed by Zukas [35] with an initial element size of $0.2 \times 0.2 \mathrm{~mm}^{2}$. Therefore, the central part (red) of our numerical model is built with 110390 finite elements and each

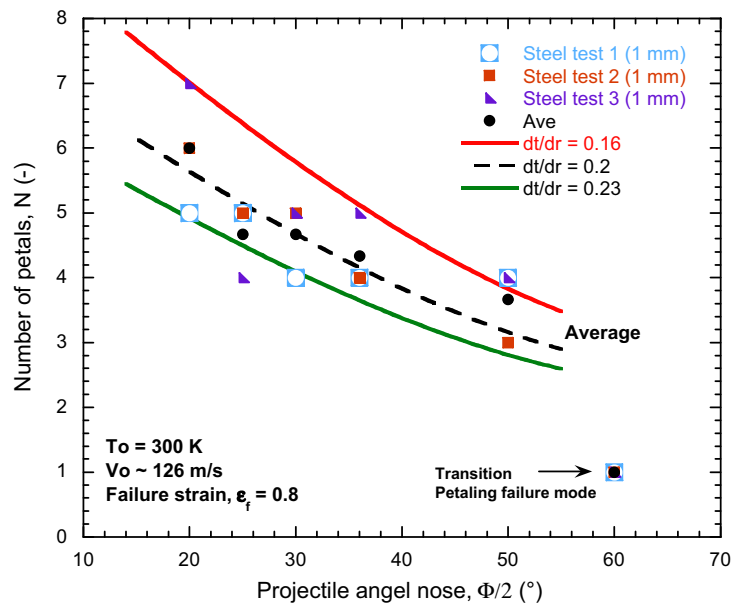

Fig. 13. Comparison between analytical predictions and experiments concerning the number of petals, $t_{0}=1 \mathrm{~mm}$ and $V_{0}=126 \mathrm{~m} / \mathrm{s}$. 


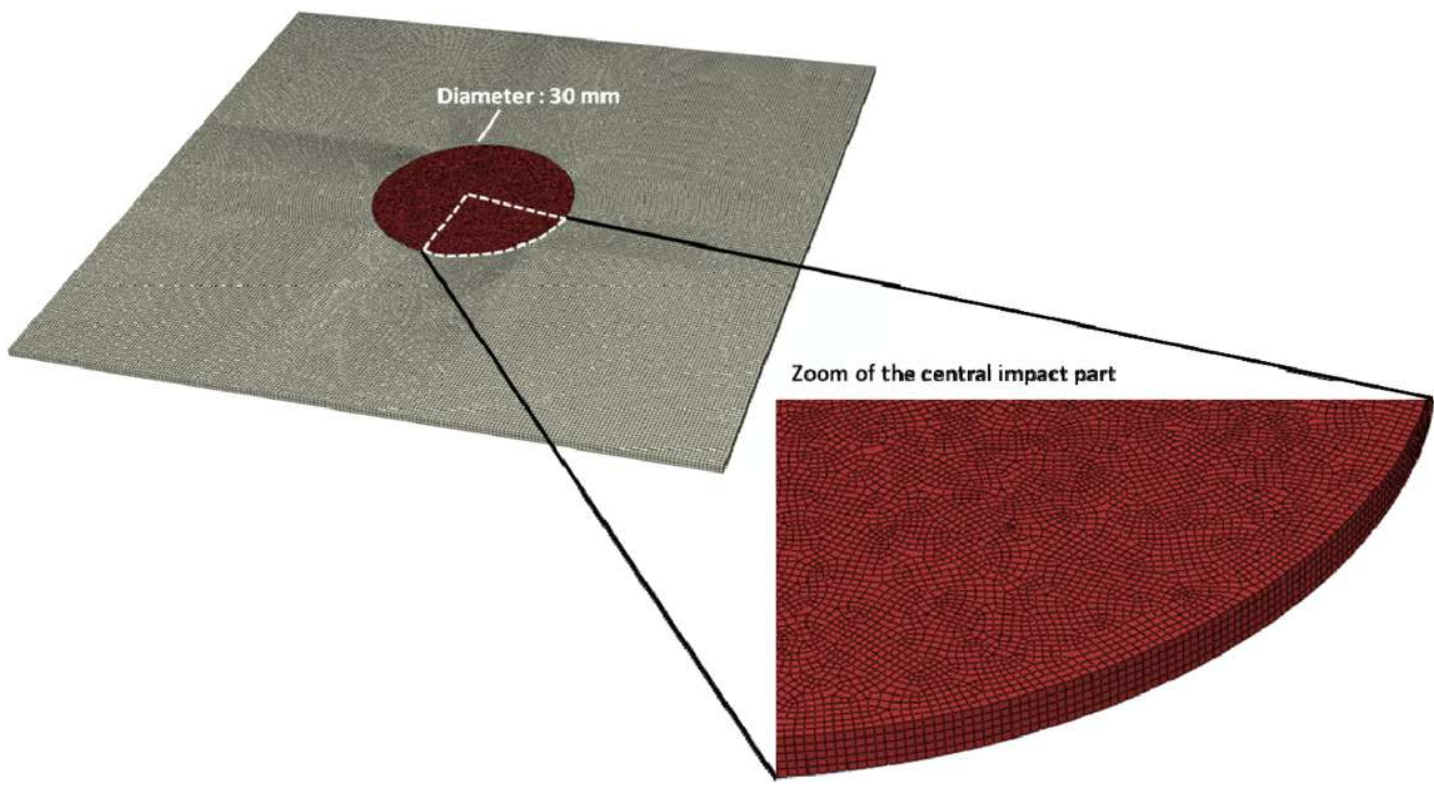

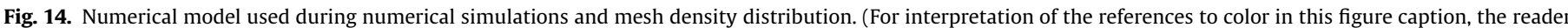
is referred to the web version of this article.)

element has a node spacing $\Delta x=\Delta y=\Delta z=0.2 \mathrm{~mm}$. Borvik et al. [3] and Rodriguez-Martinez et al. [12] used the same mesh density in the impact zone of their numerical model to avoid the effect of mesh sensitivity on the result. In the exterior part, there are 73640 finite elements and every element has a node spacing $\Delta x=\Delta y=\Delta z=0.5 \mathrm{~mm}$. For the central zone, a linear 8node brick elements reduced integration C3D8R have been used. The thickness of the plate in this area is defined using five elements. The exterior part of the plate is meshed using a linear 8-node brick incompatible mode elements C3D8I (two elements along the thickness). These finite elements are enhanced by incompatible modes to improve the bending behavior. More details on the elements used to build the numerical model are given in [36]. The constrain guarantees the continuous displacement and stress fields on the border. The interior zone of the model have a diameter of $30 \mathrm{~mm}$ allowing to initiate the process of crack propagation in a precise way without strong effect on the energy balance. The projectile behavior has been defined as elastic and a kinematic coupling constraint (rigid body) was applied allowing to avoid plastic deformation of the projectile. Penalty contact method in Abaqus/Explicit [36] is used to define the contact between the projectile and the target.

The plate has an active part of $100 \times 100 \mathrm{~mm}^{2}$ as during experiments, Fig. 3. The thermoviscoplastic material behavior of the plate is defined using the Johnson-Cook model [16,17], Eq. (7).

$\sigma=\left(A+B \varepsilon^{n}\right) \cdot\left[1+C \ln \frac{\dot{\varepsilon}}{\dot{\varepsilon}_{0}}\right] \cdot\left[1-\left(T^{*}\right)^{m}\right]$

$T^{*}=\frac{T-T_{0}}{T_{m}-T_{0}}$

where $A$ is the yield stress, $n$ is the hardening coefficient, $B$ is a constant of the material, $C$ is the strain rate sensitivity, $\dot{\varepsilon}_{0}$ is the reference strain rate, $m$ is the temperature sensitivity, $T_{m}$ is the melting temperature and $T_{0}$ is the initial temperature.

The constants used to describe the mechanical material behavior are summarized in Table 5 . They allow to take into account hardening, temperature and strain rate sensitivity. Quasistatic and dynamic tensile tests coupled to least squares method were used to define the materials constants [37].

To take into account the thermal softening of the material at high impact velocity, the previous constitutive relation, Eq. (7),
Table 5

Constants used to describe the mechanical behavior based on the Johnson-Cook model, Eq. (7), and to describe temperature increase, Eq. (8) [37].

\begin{tabular}{llllllll}
\hline$A(\mathrm{MPa})$ & $B(\mathrm{MPa})$ & $n(-)$ & $C(-)$ & $\dot{\varepsilon}_{0}(1 / \mathrm{s})$ & $T_{0}(\mathrm{~K})$ & $T_{m}(\mathrm{~K})$ & $m(-)$ \\
\hline 154 & 464 & 0.37 & 0.02 & 0.0001 & 300 & 1600 & 0.7 \\
$\beta(-)$ & & $C_{p}\left(\mathrm{~J} \mathrm{Kg}^{-1} \mathrm{~K}^{-1}\right)$ & & $\rho\left(\mathrm{kg} \mathrm{m}^{-3}\right)$ & \\
\hline 0.9 & 470 & & & & &
\end{tabular}

Table 6

Failure strain value used to simulate perforation depending on the projectile shape.

\begin{tabular}{llll}
\hline Projectile shape & Blunt & Conical & Hemispherical \\
\hline Failure strain value, $\varepsilon_{f}$ & 0.6 & 1.2 & 0.65 \\
Triaxiality, $\bar{\eta}$ & 0 & $1 / 3$ & $2 / 3$ \\
\hline
\end{tabular}

is coupled to the heat equation, Eq. (8). It allows to compute for each time increment of the plastic deformation, the actual temperature in the specimen.

$T=T_{0}+\Delta T=T_{0}+\frac{\beta}{\rho C_{p}} \int_{\varepsilon_{e}}^{\varepsilon_{f}} \sigma d \varepsilon$

where $\beta$ is the Quinney-Taylor coefficient, $\rho$ is the density of the steel sheet material, $C_{p}$ is the specific heat and $\varepsilon_{f}$ is the failure strain limit, Table 6.

During numerical simulations the influence of $\beta$ parameter on results has been studied. When $\beta$ varies from 0.8 to 1 , the variation of the residual velocity is only $\pm 0.5 \mathrm{~m} / \mathrm{s}$ if the hemispherical projectile is used and $\pm 0.2 \mathrm{~m} / \mathrm{s}$ for the other projectiles considered. It is also observed that the failure mode does not change. Therefore a constant value equal to 0.9 can be defined as a correct approximation of $\beta$ to study the process of perforation. Borvik et al. [3], Rodriguez-Martinez et al. [12] and Jankowiak et al. [38] used the same value of $\beta$ in their numerical model to simulate the perforation process. 
Based on a process of optimization for the whole range of impact velocities considered, the failure strain has been estimated depending on the projectile shape, Table 6 . The process of numerical optimization was to minimize the error on the residual velocity based on experiments, Fig. 4. The following values were obtained for each projectile shape, Table 6 . At the same time, the average triaxiality, $\bar{\eta}$, was estimated just before failure of the steel sheet [39].

It is observed that the values may be fitted using the model proposed by Wierzbicki $[40,41]$, Eq. (9). Thus based on numerical results coupled to the analyses of Wierzbicki et al. [14], an increase of the failure strain level for conical shape projectile is observed. Therefore, the model proposed by Johnson-Cook $[16,17]$ and initially implemented in Abaqus/Explicit [36] may be used just to define the case of conical and hemispherical projectile shapes contrary to the model of Wierzbicki et al. [14] which can be used to simulate the failure process for all three projectile shapes, Fig. 16.

The model reported by Wierzbicki [14] is given, Eq. (9). It allows a precise failure description including local stress triaxiality, $\eta$.

$\left\{\begin{array}{llrl}\varepsilon_{f} & =\frac{C_{1}}{1+3 \eta} & & -\frac{1}{3} \leq \eta \leq 0 \\ \varepsilon_{f} & =\varepsilon_{f, t}+\left(\varepsilon_{f, t}-\varepsilon_{f, s}\right)(3 \eta-1) & & 0 \leq \eta \leq \frac{1}{3} \\ \varepsilon_{f} & =C_{2} \exp \left(C_{3} \eta+C_{4}\right) & & \frac{1}{3} \geq \eta\end{array}\right.$
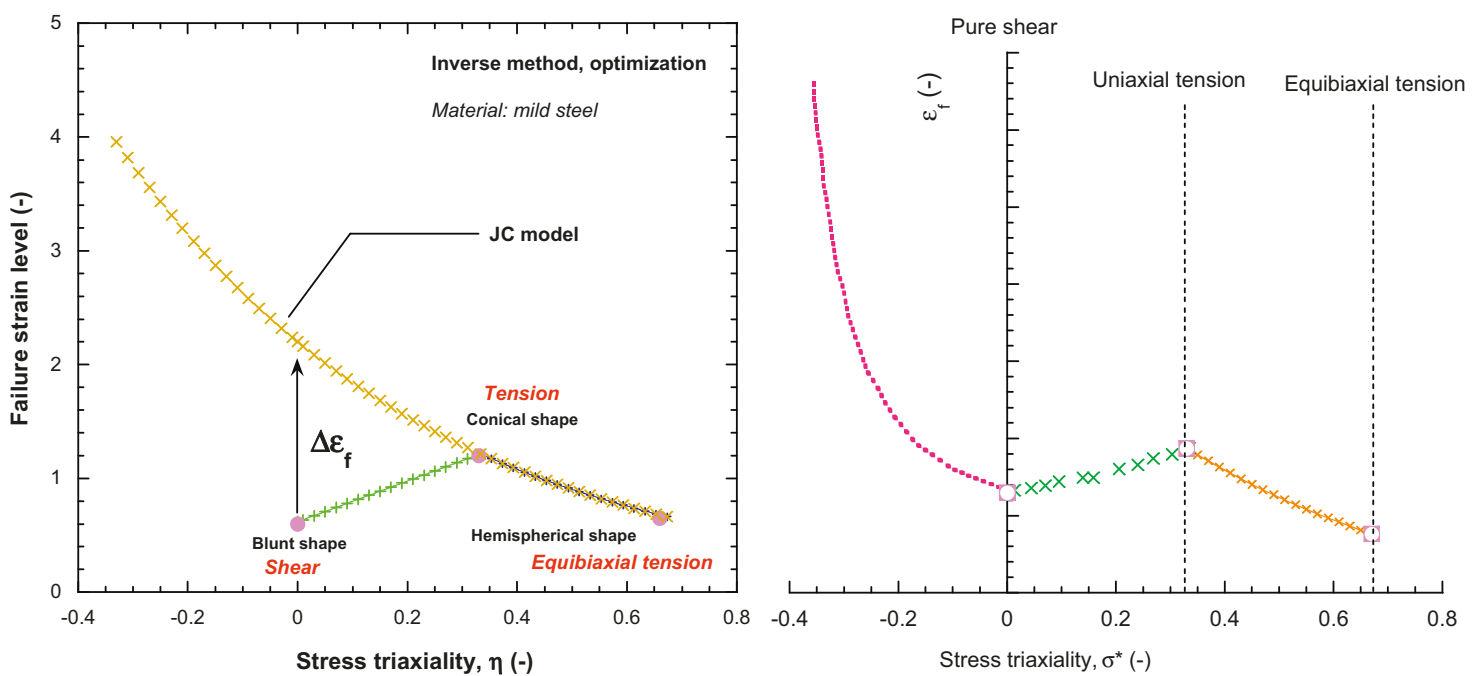

Fig. 15. Stress triaxiality effect on the failure strain level based on optimization process, (a) JC model, and (b) schematic diagram of the Wierzbicki model.
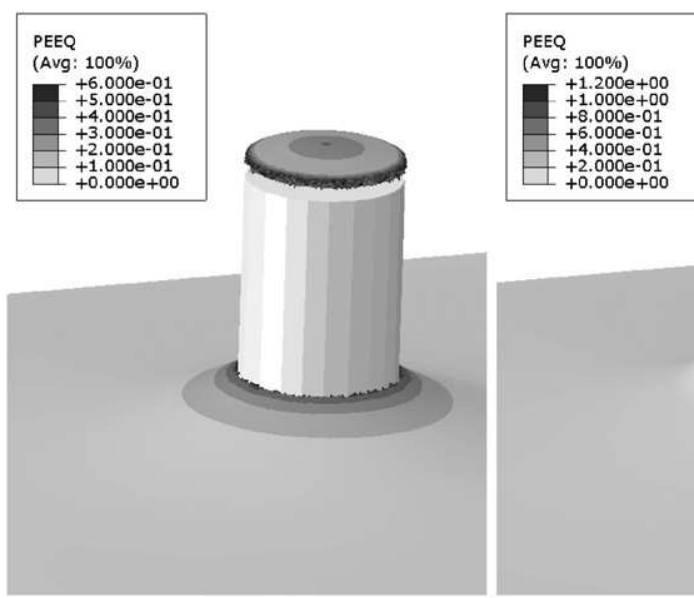

where $C_{1}, C_{2}, C_{3}$ and $C_{4}$ are the material coefficients, $\varepsilon_{f, s}$ is the shear fracture strain and $\varepsilon_{f, t}$ is the effective fracture strain.

In the model proposed by Johnson-Cook, Eq. (10), the failure strain $\varepsilon_{f}$ is assumed to be dependent of a non-dimensional strain rate $\dot{\varepsilon}_{e q}^{*}=\dot{\varepsilon} / \dot{\varepsilon}_{0}$, a dimensionless stress triaxiality $\sigma^{*}=\eta=\sigma_{m} / \bar{\sigma}$ (where $\sigma_{m}$ is the mean stress and $\bar{\sigma}$ is the equivalent stress) and a non-dimensional temperature $T^{*}$ as defined in Eq. (7).

$\varepsilon_{f}=\left(D_{1}+D_{2} \exp \left(D_{3} \sigma^{*}\right)\right)\left(1+\dot{\varepsilon}_{e q}^{*}\right)^{D_{4}}\left(1+D_{5} T^{*}\right)$

where $D_{1}, D_{2}, D_{3}, D_{4}, D_{5}$ are failure constants depending on the materials used.

Fitting the previous results, Table 6 with a part of Eq. (9) $(\eta \geq 0)$, the following description has been obtained, Fig. 15. A comparison is also made between the model reported by Wierzbicki in [14] and the Johnson-Cook model [17]. It is observed that the failure strain depends on the projectile shape due to the stress state induced. These results are in agreement with the work and analysis carried out by Wierzbicki et al. [14]. On the following curve, the failure strain obtained by optimization is reported including triaxiality dependency, Fig. 15. Additional experimental results are necessary for a complete description of the failure strain curve depending on triaxiality, especially for $\eta \leq 0$. The schematic shape of the failure curve based on the model of Wierzbicki is shown in Fig. 15b. There is a large difference between the model of JC and that of Wierzbicki for $\eta$ values less than $1 / 3$ (case of Blunt shape).

Fig. 16. Numerical result for conical, hemispherical and blunt projectile shapes, $V_{0}=120 \mathrm{~m} / \mathrm{s}$. 

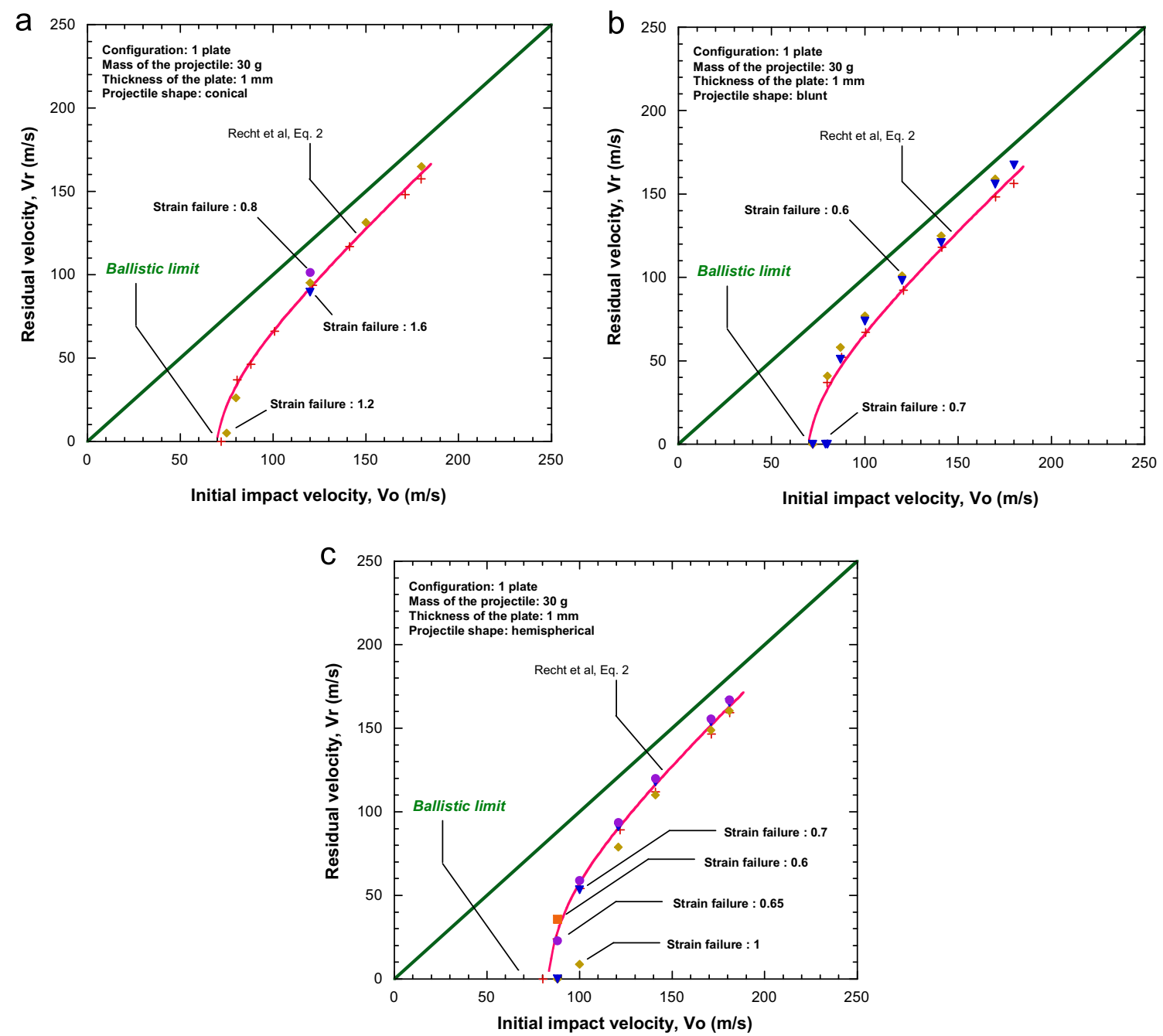

Fig. 17. Definition of the ballistic curve, comparison between experiments and numerical simulations, (a) conical projectile, (b) blunt projectile, and (c) hemispherical projectile.

Using the previous failure strain values corresponding to different projectiles shapes, all failure modes obtained experimentally Fig. 6 can be described numerically, Fig. 16. The plots clearly showed that the numerical model reflects qualitatively the overall physical behavior of the plate during penetration and perforation.

For complete validation of numerical model, the ballistic curves are plotted based on the numerical result and compared with those obtained experimentally.

\subsection{Numerical result of the ballistic curves}

The numerical results were compared with experiments in terms of ballistic curve $V_{R}-V_{0}$, Fig. 17. A good agreement is observed between numerical simulations and experiments. However, it is observed that a constant value for an imposed triaxiality (projectile shape) is not enough. In fact, it is not easy to define the whole range of impact velocities with a failure strain which does not depend on the triaxiality. To have a better description for an imposed strain level, a solution is to use a constitutive relation with a non-linear strain rate sensitivity to increase the failure energy at high impact velocity.

For a conical projectile, the experimental ballistic limit is $72 \mathrm{~m} / \mathrm{s}$, the corresponding numerical value (for failure strain level of 1.2 ) is $74 \mathrm{~m} / \mathrm{s}$. The numerical model well predicts the

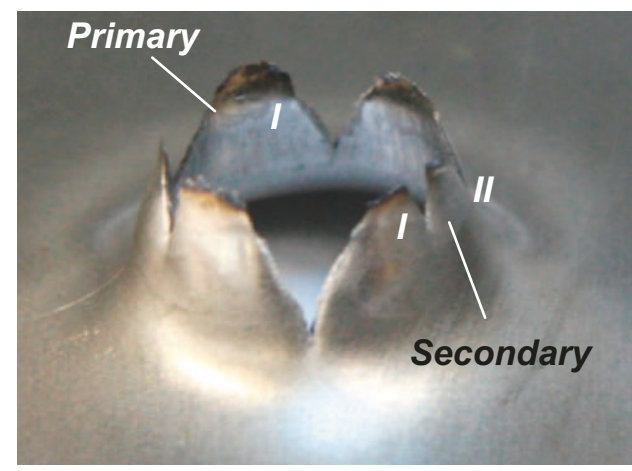

Fig. 18. Definition of petals number, primary and secondary.

ballistic limit obtained experimentally for the three types of projectiles studied, but the model overestimates around 5\% the residual velocity of the projectile at high impact velocity $\left(V_{0}>150 \mathrm{~m} / \mathrm{s}\right)$.

In order to confirm the results obtained by the analytical model of Section 3 concerning the prediction of the number of petals $N$, the numerical study was extended to this analysis. 


\subsection{Numerical prediction of the number of petals}

In addition to the ballistic curve, the number of petals $N$ has been estimated. The petals have been defined as primary and secondary, Fig. 18, allowing to define a minimum and a maximum numbers of petals experimentally and numerically.

Using the previous definition, the following results have been obtained, Fig. 19. A good agreement is observed between experimental results and numerical simulations for the range of angle considered, $20 \leq \phi / 2 \leq 60^{\circ}$. The petals number $N$ is decreasing with the nose projectile angle similarly as during experiments.

In the following figures, some numerical results are reported showing the projectile nose angle effect on the failure mode and the number of petals, Fig. 20. For $\phi / 2=60^{\circ}$, the failure mode by plug ejection occurs in agreement with experiments, Fig. 12.

The transition in the failure modes from petaling to plug ejection occurs when the projectile nose angle is greater than $50^{\circ}$ as experimentally observed, Fig. 12 .

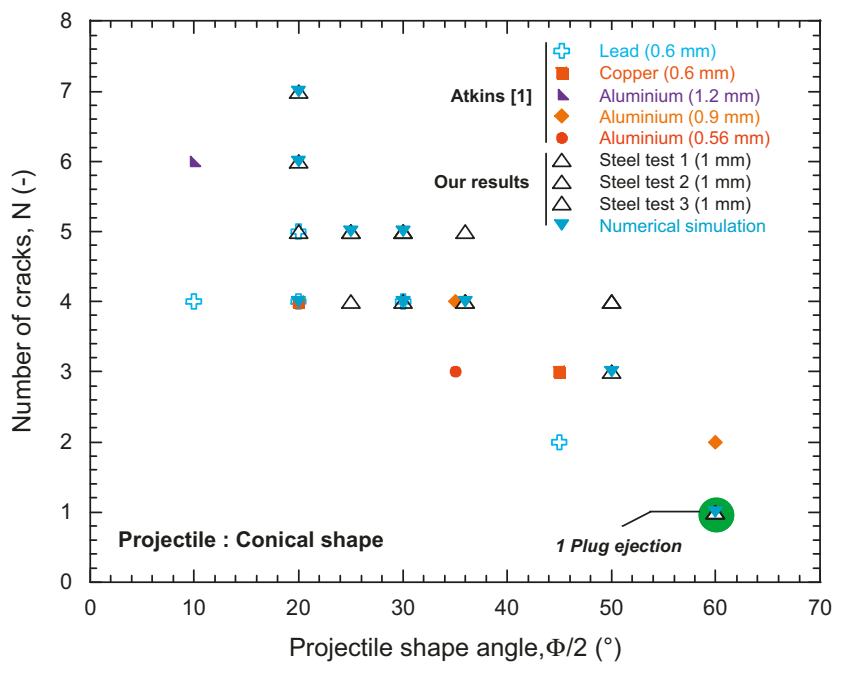

Fig. 19. Experimental and numerical results of the number of petals as function of the projectile shape angle, $V_{0}=126 \mathrm{~m} / \mathrm{s}$.

\section{Conclusions}

Mild steel plates of $1 \mathrm{~mm}$ thickness have been impacted in our investigation using conical, blunt and hemispherical shape projectiles $13 \mathrm{~mm}$ in diameter. The mass ratio (projectile mass/steel sheet mass) was equal to 0.38 and the ratio between the span of the steel sheet and the projectile diameter is 3.85. We have found the ballistic limit for each kind of projectile and the ballistic curves have been plotted. An increase of the ballistic limit $V_{B}$ is observed for a hemispherical shape projectile, compared to blunt or conical shape. It is shown that the energy absorbed by the steel sheet at high impact velocity, up to $170 \mathrm{~m} / \mathrm{s}$ is approximately the same for all three projectile shapes. As observed in this work, the failure mode of the sheet steel used is strongly correlated to the projectile shape. Using a blunt shape projectile, the plate fails by plug ejection due to the process of high shearing, whereas for a conical shape projectile a petaling failure mode is observed inducing radial necking due to radial tension. Finally, considering hemispherical shape projectile, plug ejection failure mode is observed due to a circumferential necking. Numerical simulations have been performed using Abaqus/Explicit finite element code. The numerical model allows to predict accurately the impact failure mode as observed during experiments depending on the nose shape. Good agreement is found between experimental results and the FE simulations in terms of residual velocity ballistic curves.

In order to take into account the influence of the thickness of the plate on the perforation process, a sandwich configuration has been proposed ( up to four plates). A non-linear increase of the ballistic limit and the energy absorbed $W_{\text {plate }}$ with the thickness of the plate using conical shape projectile is noticed. In the case of a 4-plate configuration, there is a mix of different failure modes (circumferential necking to petaling failure mode) according to the position of the plate in the layered configuration.

A more detailed study on the effect of the vertex angle of conical shape projectile on the process of perforation has been made. A decrease of the number of petals with the nose angle is observed. An analytical model for the number of petals prediction proposed by Atkins et al. [1] has been used. A qualitative agreement is found between experimental results and the model
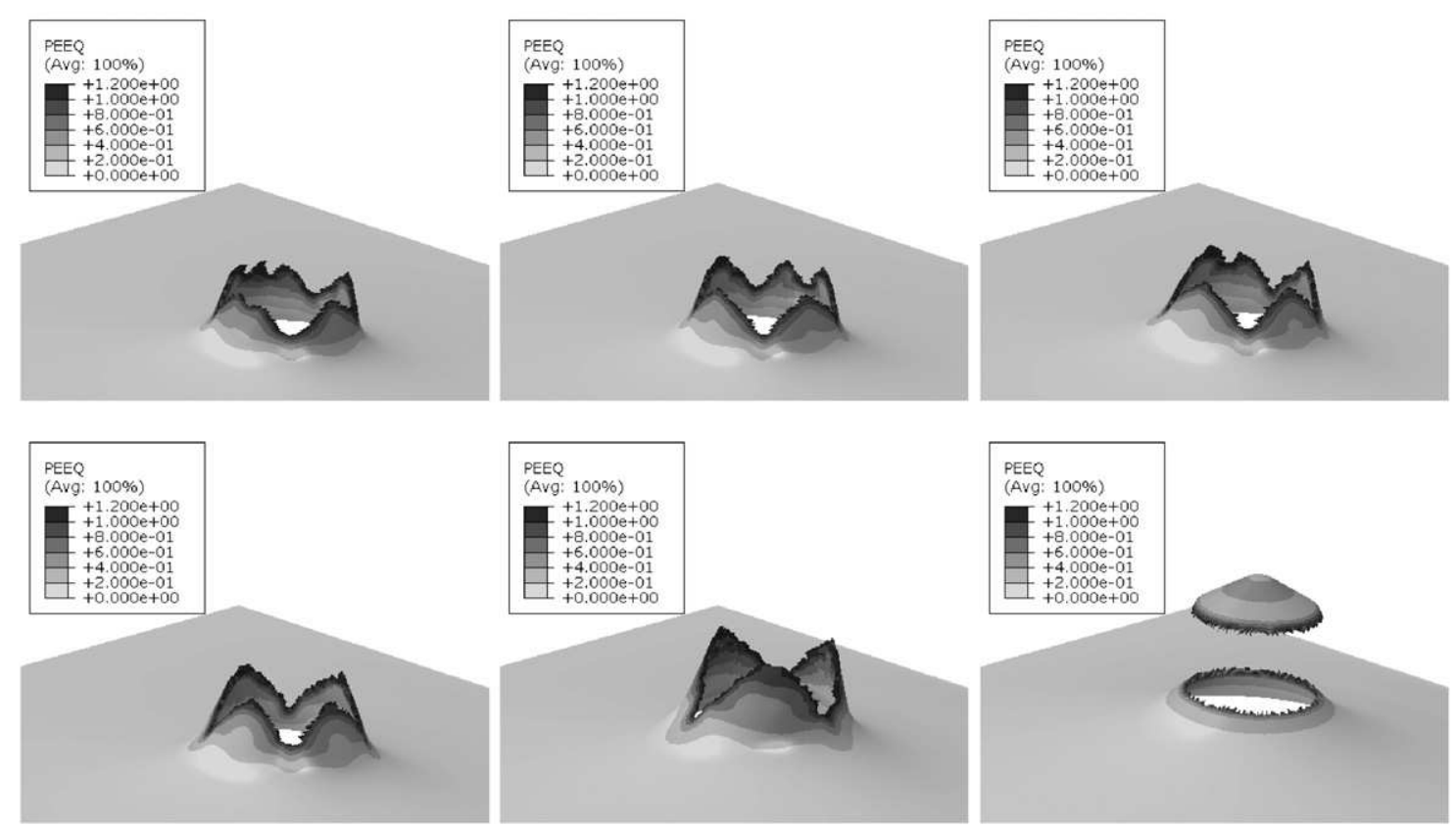

Fig. 20. Numerical results in term of nose angle on the number of petals, $20^{\circ}, 25^{\circ}, 30^{\circ}, 36^{\circ}, 50^{\circ}$ and $60^{\circ}, V_{\mathrm{o}}=126 \mathrm{~m} / \mathrm{s}$. 
prediction. It shows the importance of taking in to account the adiabatic heat effect on the equivalent strain. The trend of a decreasing number of petals as the cone angle increases has been also well predicted by FE simulations.

\section{Acknowledgments}

Authors thank Ministry of Science and Higher Education of Poland for financial support under Grants: R00 0097 12. Authors thank also M. Tavian technician in electronics from ENIM for his contribution on the development of the residual velocity measurement sensors.

\section{References}

[1] Atkins AG, Afzal Khan M, M. Liu JH. Necking and radial cracking around perforations in thin sheets at normal incidence. International Journal of Impact Engineering 1998;21(7):521-39.

[2] Borvik T, Langseth M, Hoperstad OS, Malo KA. Perforation of $12 \mathrm{~mm}$ thick steel plates by $20 \mathrm{~mm}$ diameter projectiles with flat, hemispherical and conical noses part I: experimental study. International Journal of Impact Engineering 2002;27:19-35.

[3] Borvik T, Langseth M, Hoperstad OS, Malo KA. Perforation of $12 \mathrm{~mm}$ thick steel plates by $20 \mathrm{~mm}$ diameter projectiles with flat, hemispherical and conical noses part II: numerical study. International Journal of Impact Engineering 2002;27:37-64.

[4] Borvik T, Hoperstad OS, Langseth M, Malo KA. Effect of target thickness in blunt projectile penetration of Weldox $460 \mathrm{E}$ steel plates. International Journal of Impact Engineering 2003;28:413-64.

[5] Dey S, Borvik T, Hopperstad OS, Leinum JR, Langseth M. The effect of target on the penetration of steel plates using three different projectile nose shapes. International Journal of Impact Engineering 2004;30:1005-38.

[6] Rusinek A, Rodríguez-Martínez JA, Zaera R, Klepaczko JR, Arias A, Sauvelet C. Experimental and numerical study on the perforation process of mild steel sheets subjected to perpendicular impact by hemispherical projectiles. International Journal of Impact Engineering 2009;36:565-87.

[7] Backman ME, Goldsmith W. The mechanics of penetration of projectiles into targets. International Journal of Engineering Science 1978:16:1-99.

[8] Chen XW, Huang XL, Liang GJ. Comparative analysis of perforation models of metallic plates by rigid sharp-nosed projectiles. International Journal of Impact Engineering 2011;38:613-21.

[9] Forrestal MJ, Warren TL. Perforation equations for conical and ogival nose rigid projectiles into aluminum target plates. International Journal of Impact Engineering 2009;36:220-5.

[10] Chen XW, Li QM. Perforation of a thick plate by rigid projectiles. International Journal of Impact Engineering 2003;28(7):743-59.

[11] Wierzbicki T. Petalling of plates under explosive and impact loading. International Journal of Impact Engineering 1999;22:935-54

[12] Arias A, Rodríguez-Martínez JA, Rusinek A. Numerical simulations of impact behaviour of thin steel to cylindrical, conical and hemispherical nondeformable projectiles. Engineering Fracture Mechanics 2008;75:1635-56.

[13] Wierzbicki T, Bao Y. Calibration and evaluation of seven fracture models. International Journal of Mechanical Sciences 2005;47:719-43.

[14] Mae H, Teng X, Bai Y, Wierzbicki T. Comparison of ductile fracture properties of aluminum castings: Sand mold vs. metal mold. International Journal of Solids and Structures 2008;45:1430-44.

[15] Alavi Nia A, Hoseini GR. Experimental study of perforation of multi-layered targets by hemispherical-nosed projectiles. Materials \& Design 2011;32(2): 1057-65.

[16] Johnson GR, Cook WH., 1983, A constitutive model and data for metals subjected to large strains, high strain rates and high temperatures. In: Proceedings of 7th international symposium on ballistics; 1983, p. 541-7.
[17] Johnson GR, Cook WH. Fracture characteristics of three metals subjected to various strain, strain rates, temperatures and pressures. Engineering Fracture Mechanics 1985;21(1):31-48.

[18] Rodríguez-Martínez JA, Rusinek A, Chevrier P, Bernier R, Arias A. Temperature measurements on ES steel sheets subjected to perforation by hemispherical projectiles. International Journal of Impact Engineering 2010;37:828-41.

[19] Rodríguez-Martínez JA, Rusinek A, Arias A. Relation between strain hardening of steel and critical impact velocity in tension. Journal of Theoretical and Applied Mechanics 2009;43(3):645-65.

[20] Dean J, Dunleavy CS, Brown PM, Clyne TW. Energy absorption during projectile perforation of thin steel plates and the kinetic energy of ejected fragments. International Journal of Impact Engineering 2009;36:1250-8.

[21] Rusinek A, Zaera R, Klepaczko JR. Constitutive relations in 3-D for a wide range of strain rates and temperatures - application to mild steels. International Journal of Solids and Structures 2007;44(17):5611-34.

22] Scheffler DR, Zukas JA. Practical aspects of numerical simulations of dynamic events: effects of meshing. International Journal of Impact Engineering 2000;24(9):925-45.

[23] Zukas JA, Scheffer DR. Impact effects in multilayered plates. International Journal of Solids and Structures 2001;38(19):3321-8.

[24] Rusinek A, Rodríguez-Martínez JA, Zaera R, Klepaczko JR, Arias A, Sauvelet C. Experimental and numerical study on the perforation process of mild steel sheets subjected to perpendicular impact by hemispherical projectiles. International Journal of Impact Engineering 2009;36:565-87.

[25] Recht RF, Ipson TW. Ballistic perforation dynamics. Journal of Applied Mechanics 1963;30:384.

[26] Landkof B, Goldsmith W. Petaling of thin, metallic plates during penetration by cylindro-conical projectiles. International Journal of Solids and Structures 1993;21:245-66.

27] Iqbal MA, Gupta NK. Energy absorption characteristics of aluminum plates subjected to projectile impact. Latin American Journal of Solids and Structures 2008;5:259-87.

[28] Corbett GG, Reid SR, Johnson W. Impact loading of plates and shells by freeflying projectiles: a review. International Journal of Impact Engineering 1996;18:141-230.

[29] Corran RSJ, Shadbolt PJ, Ruiz C. Impact loading of plates: an experimenta investigation. International Journal of Impact Engineering 1983;1:3-22.

[30] Teng X, Dey S, Børvik T, Wierzbicki T. Protection performance of doublelayered metal shields against projectile impact. Journal of Mechanics of Materials and Structures 2007;2:1307-28.

[31] Dey S, Børvik T, Teng X, Wierzbicki T, Hopperstad OS. On the ballistic resistance of double-layered steel plates: an experimental and numerica investigation. International Journal of Solids and Structures 2007;44 6701-23.

[32] Rusinek A, Nowacki WK, Gadaj P. Measurement of temperature coupling by thermovision and constitutive relation at high strain rates for the dual phase sheet steel. Journal of Physics 2003;110:411-6.

[33] Jankowiak T, Rusinek A Lodygowski T. Validation of the KlepaczkoMalinowski model for friction correction and recommendations on Split Hopkinson Pressure Bar. Finite Elements in Analysis and Design 2011;47 1191-208.

[34] Rusinek A, Klepaczho JR. Effect of adiabatic heating in some processes of plastic deformation. Impact Engineering Applications 2001;I and II:541-6.

[35] Zukas JA, Scheffler DR. Practical aspects of numerical simulations of dynamic events: effects of meshing. International Journal of Impact Engineering 2000:925-45.

[36] ABAQUS, 2011, abaqus/explicit user's manuals, version 6.11

[37] Kpenyigba M, Rusinek A., Mechanical behaviour and thermoviscoplastic modeling of mild steel sheet, 2012, internal report LaBPS-ENIM.

[38] Jankowiak T, Rusinek A, Wood P. A numerical analysis of the dynamic behaviour of sheet steel perforated by a conical projectile under ballistic conditions. Finite Elements in Analysis and Design 2013;65:39-49.

[39] Lee YW, Wierzbicki T. Fracture prediction of thin plates under localized impulsive loading. Part II: discing and petaling. International Journal of Impact Engineering 2005;31:1277-308.

[40] Bao Y, Wierzbicki T. On the cut-off negative triaxiality for fracture. Engineering Fracture Mechanics 2005;72:1049-69.

[41] Teng X, Wierzbicki T. Evaluation of six fracture models in high velocity perforation. Engineering Fracture Mechanics 2006;73:1653-78. 